\title{
Molho cremoso à base de extrato de soja: estabilidade, propriedades reológicas, valor nutricional e aceitabilidade do consumidor
}

\author{
Soy - based low fat emulsion: stability, rheology, nutritional value and consumer acceptance
}

\author{
Denise Carvalho Pereira CAMPOS ${ }^{1}$, Rosemar ANTONIASSI ${ }^{2}$, \\ Rosires DELIZA ${ }^{2 *}$, Sidinéa Cordeiro de FREITAS², Ilana FELBERG ${ }^{2}$
}

\begin{abstract}
Resumo
Na preparação de molhos de salada substitutos da maionese, para reduzir a quantidade de ovos e de óleo são utilizados emulsificantes e espessantes associados ou não à proteína de soja. Neste trabalho, o extrato de soja integral homogeneizado foi utilizado como base para a preparação de emulsão cremosa para substituir a maionese. O extrato de soja foi elaborado com teor de sólidos totais de 6 a $12 \%$, após cozimento em água com bicarbonato, trituração e homogeneização a alta pressão. A emulsão preparada com diversas proporções de extrato de soja e óleos de soja e girassol foi também submetida à homogeneização a alta pressão variando de 1000 a 4000 psi. Na formulação do molho cremoso foram utilizados: açúcar, sal, ácido cítrico e diferentes hidrocolóides como estabilizantes. Os produtos foram avaliados quanto às características nutricionais, sensoriais, reológicas e de estabilidade. As condições mais favoráveis quanto à estabilidade e comportamento reológico para obtenção de molho cremoso foram atingidas quando se utilizou extrato de soja com 10\% de sólidos, pressão de homogeneização de 3000 psi e relação extrato:óleo de 70:30, condição que apresentou redução de calorias de até 60\%, em relação à maionese. Não foi observada diferença significativa $(\mathrm{p}<0,05)$ quanto à preferência em relação ao sabor e consistência, bem como considerando a intenção de compra para as amostras de molho cremoso preparadas com os óleos de soja e girassol, utilizando-se como estabilizantes a goma xantana, maltodextrina ou carboximetilcelulose. O produto final é livre de colesterol, apresenta a vantagem do maior conteúdo proteico e teor reduzido de óleo e de calorias, além de adequada aceitação pelo consumidor, em relação à maionese tradicional e molhos para saladas.

Palavras-chave: extrato de soja integral; emulsão de baixa caloria; análise sensorial; consumidor.
\end{abstract}

\begin{abstract}
The salad dressing preparation, which replaces for replacing the mayonnaise, uses utilizes emulsifiers and thickeners related or not to the soy protein in order to reduce the egg and oil quantity. In the The present work, used homogenized whole soymilk was used to prepare a creamy low-fat emulsion to replace traditional mayonnaise. The whole soymilk was elaborated with $6-12 \%$ of solids after cooking with bicarbonate, grinding and homogenizing it under high pressure. The emulsion was prepared with several proportions of soymilk and sunflower and soybean oils and was also submitted to high-pressure homogenization, under high pressure, which varied from 1000 to 4000 psi. Sugar, salt, citric acid and different hydrocolloids were used in the creamy sauce formulation as stabilizers. The products were evaluated according to their nutritional, sensory and physical properties (stability and viscosity). The more favored conditions regarding the stability and rheological behavior of the creamy low-fat emulsion were reached with $10 \%$ of solids, at 3000 psi and the proportion of 70:30 soymilk:oil (v/v). The product underfrom such conditions presented a calorie reduction of up to $60 \%$ compared to the mayonnaise. No significant difference was observed $(\mathrm{p}<0.05)$ on consumer flavor and consistency acceptance, norneither in relation to the purchase intention of the samples prepared with soybean and sunflower oils, and xanthan gum, maltodextrine or CMC as thickener agents. The final product is cholesterol free and has the advantage of a higher protein content, reduced oil and calories, in addition tobesides an adequate consumer acceptance when compared to traditional mayonnaise and other salad dressings.

Keywords: whole soymilk, low fat emulsion, sensory evaluation, consumer.
\end{abstract}

\section{Introdução}

O aumento do consumo de soja (principalmente das bebidas à base de soja, que tiveram um incremento de $30 \%$ ) pode estar relacionado à percepção favorável do consumidor em relação à alta qualidade da proteína e o baixo nível de óleo e colesterol dos produtos de soja (LAKSHMANAN; LAMBALLERIE; JUNG, 2006).

A busca do consumidor por alimentos mais nutritivos tem sido observada como tendência no mundo globalizado, favorecendo as pesquisas de desenvolvimento de produtos que atendam a tal anseio (SLOAN, 2005; STEWART-KNOX; MITCHELL, 2003).

A maionese é provavelmente o molho mais utilizado no mundo, composta de ovos, vinagre e condimentos, apresentando de 70 a $80 \%$ de óleo. Apesar do seu conteúdo de colesterol, o ovo é o agente emulsificante mais utilizado. Na preparação de substitutos de maionese com menor teor de óleo e de ovos,

Recebido para publicação em 13/3/2008

Aceito para publicação em 28/10/2008 (003319)

1 Fundação de Amparo à Pesquisa do Estado do Rio de Janeiro - FAPERJ

${ }^{2}$ Embrapa Agroindústria de Alimentos, Av. das Américas, 29501, CEP 23020-470, Rio de Janeiro - RJ, Brasil, E-mail: rodeliza@ctaa.embrapa.br

${ }^{*}$ A quem a correspondência deve ser enviada 
ocorre, em paralelo, a redução da estabilidade da emulsão, que pode ser aumentada pela ação de proteínas, maltodextrina e gomas (DEPREE; SAVAGE, 2001).

Alguns ingredientes e aditivos são utilizados para substituir ou reduzir a quantidade de gorduras nas formulações, mas mantendo ainda as características de textura desses produtos. Os substitutos de gordura podem ser derivados de amido, de proteína de soro de leite, além de hidrocolóides como gomas, pectina, celulose e gelatina, entre outros, que devido à capacidade de absorver água proporcionam a percepção dos atributos de textura semelhante às formulações com gorduras (AKOH, 1995; GIESE, 1996; GROSSKLAUS, 1996).

Entre essas opções, os derivados de soja têm grande destaque na preparação de produtos cárneos ou nas emulsões do tipo óleo em água devido à capacidade de emulsificar e estabilizar as emulsões, além de aumentar o conteúdo de proteína e reduzir o conteúdo de gordura (GIESE, 1996; PATEL; GUPTA, 1988).

Estão disponíveis no mercado brasileiro molhos que se assemelham à maionese que utilizam proteína de soja ou aditivos como gomas ou amido para reduzir a quantidade de ovos e de óleo.

Wang, Paula e Moraes (1991) e Paula (1991) prepararam uma "maionese de soja" com extrato de soja obtido pelo método convencional (com filtração para separação de insolúveis), com preparação da emulsão em liquidificador, tendo melhores resultados nas proporções de óleo:extrato de soja de 40:58 e 34:64 e até $1 \mathrm{~g}$ de ácido cítrico.

O objetivo deste trabalho foi desenvolver um molho cremoso como substituto da maionese tradicional, com adequadas características sensoriais e nutricionais, porém com reduzido teor de óleo e livre de colesterol. O molho foi preparado a partir de uma emulsão à base de extrato de soja integral homogeneizado a alta pressão e óleo vegetal, com adição de estabilizantes. A avaliação do molho foi realizada a partir de suas características reológicas, nutricionais e sensoriais.

\section{Material e métodos}

\subsection{Matéria-prima}

A soja (Glycine max) utilizada na preparação do extrato de soja integral foi da variedade BR-16. Os óleos de soja e girassol refinados, o açúcar, sal e bicarbonato de sódio foram adquiridos no comércio local. Os espessantes/estabilizantes utilizados foram produtos comerciais de celulose microcristalina (Novagel TM RCN-10 Cellulose Gel da FMC), goma xantana (marca A: Rhodigel 200 da Rhodia e marca B: Nutra Sweet da Kelco Company), carboximetilcelulose (CMC da Granotec), amido modificado e maltodextrina (N-LITE® L Food starch modified e N-LITE® D - Food grade maltodextrin).

\subsection{Processamento}

A emulsão foi preparada a partir de mistura de extrato de soja integral (de conteúdos de sólidos totais de 6 a $12 \%$ e homogeneizado à pressão de 5000 psi) e óleo de soja, nas relações de extrato:óleo de 70:30, 60:40 e 50:50. A emulsão foi também homogeneizada a alta pressão variando de 1000 a 4000 psi. Estas amostras foram avaliadas nos ensaios de estabilidade quanto à separação de fases. A avaliação do comportamento reológico foi realizada para as amostras de emulsão preparadas com extrato com 8 e $10 \%$ de sólidos totais.

O extrato de soja considerado mais adequado à preparação de molho cremoso formulado foi selecionado considerando-se critérios de estabilidade. A emulsão foi preparada utilizando este extrato se soja integral de $10 \%$ de sólidos e óleos de soja e girassol (nas proporções de 70:30, 60:40 e 50:50 extrato:óleo v/v), e adicionaram-se sal, açúcar e espessantes e, então, utilizou-se a designação de molho cremoso. A homogeneização do molho cremoso foi realizada a 3000 psi. As amostras de molho cremoso foram avaliadas quanto à estabilidade e comportamento reológico.

As amostras de molho que apresentaram maior redução calórica (70:30) foram comparadas em ensaio de avaliação sensorial.

\section{Obtenção de extrato de soja integral}

Os grãos de soja descascados foram cozidos na temperatura de ebulição durante 30 minutos em solução de bicarbonato de sódio a $0,25 \%$ na proporção de 1:3 (soja:solução). Os grãos cozidos e lavados foram desintegrados com água à temperatura de ebulição em desintegrador industrial Waring Blender na proporção de água calculada para se obter o teor de sólidos adequado para o extrato (de 6 a $12 \%$ peso/volume). Em seguida, o extrato foi homogeneizado em homogeneizador contínuo APV Gaulin, modelo $15 \mathrm{MR}$, com dois estágios, aplicando-se pressão total de 5000 psi, com 4500 no primeiro estágio e 500 psi no segundo estágio (FELBERG et al., 2004).

\section{Preparação da emulsão}

A emulsão foi preparada imediatamente após a obtenção do extrato de soja, com adição de óleo ao extrato diretamente no desintegrador industrial Waring Blender sob agitação alta durante 5 a 15 segundos, dependendo da quantidade de óleo na emulsão. A emulsão foi preparada nas seguintes proporções de extrato de soja:óleo de 70:30, 60:40 e 50:50 volume/volume. Em seguida, a emulsão foi homogeneizada no mesmo equipamento utilizado para o extrato, com pressão de homogeneização de 1000 a 4000 psi.

\section{Formulação da emulsão para preparação do molho cremoso}

Os aditivos foram adicionados diretamente no extrato antes da adição do óleo, nas proporções de 1\% de sal; 0,8\% de açúcar; 0,2\% de ácido cítrico; e 0,1\% de espessante (peso/volume da emulsão). Cada emulsão foi preparada num volume de 2 litros/ensaio e depois de formulada foi chamada de molho cremoso.

\subsection{Avaliação físico-química}

As análises físico-químicas foram realizadas segundo os métodos oficiais da AOAC (2005) no extrato de soja com $10 \%$ 
de sólidos que foi utilizado nos ensaios da análise sensorial. $\mathrm{O}$ teor de água no extrato foi determinado em estufa sob vácuo, segundo o método oficial 925.45 (44.1.03). O teor de proteína foi calculado utilizando-se fator de 6,25 a partir do conteúdo de nitrogênio total determinado por Kjeldahl de acordo com o método 991.20 (33.2.11). O teor de lipídios foi realizado por hidrólise ácida (método 922.06). Os teores de cinzas e de fibra bruta foram determinados segundo os métodos oficiais 923.03 (32.1.05) e 962.09 (4.6.01), respectivamente.

A estabilidade de todas as amostras de emulsão e de molho cremoso foi avaliada em geladeira (temperatura de $10^{\circ} \mathrm{C}$ ) e em freezer (temperatura de $-25^{\circ} \mathrm{C}$ ), pela observação de quebra de emulsão, sinérese e formação de duas fases, segundo informações de empresa produtora de maionese. As amostras foram colocadas em béquer de $100 \mathrm{~mL}$ de mesmo formato, na mesma altura e cobertas com filme plástico. $\mathrm{Na}$ avaliação das amostras a cada 7 dias ou a cada dia, respectivamente, para amostras armazenadas a 10 e $-25^{\circ} \mathrm{C}$, o frasco foi retirado e, após atingir a temperatura ambiente, foi observado quanto à estabilidade.

O comportamento reológico de todas as amostras de emulsão e de molho cremoso foi avaliado após sete dias de seu preparo, pois as maiores mudanças nos parâmetros reológicos ocorrem na primeira semana de armazenamento, que é o tempo necessário para se atingir o equilíbrio da emulsão (STERN; VALENTOVA; POKORNY, 2001). As propriedades reológicas foram determinadas em viscosímetro de cilindros coaxiais Contraves Rheomat 30 com programador (Rheomat 100); banho termostático (Rheomat115) e registrador Gráfico (Rikadenki); e sistema de medida DIN 14 e DIN 25, a $25^{\circ} \mathrm{C}$ que é a temperatura mais próxima para consumo. Os ensaios de curva de escoamento foram realizados dentro do intervalo de taxa de deformação entre 0 a $450 \mathrm{~s}^{-1}$ (primeiro ciclo).

Para as curvas obtidas foi aplicado o modelo da lei de potência descrito pela Equação 1, utilizando-se o Excel e para ajuste foi utilizado como critério o coeficiente de determinação $\mathrm{R}^{2}$ e foram calculados o $\mathrm{K}$ e $\mathrm{n}$, conforme:

$\sigma=\mathrm{K}(\gamma)^{\mathrm{n}}$

onde:

$\sigma$ é a tensão de cisalhamento $(\mathrm{mPa})$;

K é o índice de consistência $\left(\mathrm{mPas}^{\mathrm{n}}\right)$;

$\gamma$ é a taxa de deformação (1/s); e

n é o índice de comportamento reológico.

As análises de acidez e índice de peróxidos dos óleos de soja e girassol foram realizadas segundo os métodos oficiais da AOCS (2004), respectivamente, Ca 5 a 40 e Cd 8-53.

A determinação do índice de estabilidade oxidativa dos óleos de soja e girassol foi realizada no aparelho Rancimat $679 \mathrm{Metrohm}$, com $5 \mathrm{~g}$ de óleo, fluxo de ar de 8,33 L/hora, temperatura de $98^{\circ} \mathrm{C}$, de acordo com o método oficial Cd 12b-92.

Para análise da composição em ácidos graxos dos óleos de soja e girassol, os ésteres metílicos foram preparados de acordo com o método Hartman e Lago (1973) e analisados por cromatografia a gás de alta resolução, em aparelho HP 5890, equipado com detector de ionização de chama operado a $280{ }^{\circ} \mathrm{C}$. Utilizou-se coluna capilar de sílica fundida de filme de cianopropilssiloxano $(60 \mathrm{~m} \times 0,32 \mathrm{~mm} \times 0,25 \mu \mathrm{m})$, com programação de temperatura de 180 a $210{ }^{\circ} \mathrm{C} \mathrm{e} 2{ }^{\circ} \mathrm{C} /$ minuto. Foi injetado $1 \mu \mathrm{L}$ de amostra em injetor aquecido a $250{ }^{\circ} \mathrm{C}$, operado no modo de divisão de fluxo de 1:50. A identificação foi realizada por comparação dos tempos de retenção com os padrões da NU-CHEK Prep. Inc. (Elysian, $\mathrm{MN}$ ) e a quantificação foi por normalização interna.

\subsection{Avaliação sensorial}

As amostras que apresentaram uma maior redução calórica, em relação à maionese tradicional (molhos preparados na relação 70:30 extrato de soja:óleo), foram submetidas a teste para identificação do molho cremoso preferido pelo consumidor. Todos os produtos foram processados na Planta Piloto da Embrapa Agroindústria de Alimentos na semana anterior ao teste e mantidos em geladeira a $5^{\circ} \mathrm{C}$. Três formulações de molho cremoso preparadas com óleo de soja e obtidas com variação no espessante utilizado foram avaliadas por 85 consumidores (55 mulheres e 30 homens) quanto à preferência em relação ao sabor e consistência. A intenção de compra dos participantes para cada amostra também foi verificada.

As amostras foram apresentadas sobre torradas quadradas de 2,5 cm de lado. O teste foi realizado em cabines individuais de prova sob iluminação branca, a fim de possibilitar a visualização da aparência dos produtos. As amostras foram servidas monadicamente, codificadas com número de três dígitos, acompanhadas de água mineral em temperatura ambiente para lavagem do palato entre uma amostra e outra.

A ordem de apresentação das amostras foi balanceada e utilizou-se a escala hedônica de nove pontos variando de "desgostei extremamente" a "gostei extremamente", tanto para a avaliação do sabor quanto da consistência. Para a avaliação da intenção de compra dos produtos, os consumidores utilizaram escala estruturada de sete pontos. O teste foi realizado nas cabines de prova entre 10 horas e 16 horas e 30 minutos.

O experimento foi repetido com as amostras contendo óleo de girassol. Os espessantes foram os mesmos utilizados anteriormente e a avaliação seguiu o mesmo delineamento apresentado para as amostras de óleo de soja. O número de participantes do teste foi de 80 consumidores, sendo 52 mulheres e 28 homens.

Os participantes de ambos os estudos foram informados sobre os objetivos do projeto antes de iniciarem as avaliações e receberam um formulário de consentimento que explicava os referidos objetivos e esclarecia sobre o sigilo envolvendo seus nomes em qualquer publicação falada ou escrita, bem como deixava claro que as amostras tinham sido preparadas sob adequadas condições higiênico-sanitárias. Foi esclarecido também que poderiam se retirar do estudo a qualquer momento. Tal termo foi assinado por cada um deles e retornado ao responsável pelo teste.

Os dados da avaliação sensorial foram analisados através da Análise de Variância e teste de Tukey para checar diferença entre as médias. 


\section{Resultados e discussão}

\subsection{Estabilidade e comportamento reológico da emulsão}

As características das amostras de emulsão e os resultados de estabilidade estão relatados na Tabela 1.

Foi observada maior estabilidade da emulsão a $-25^{\circ} \mathrm{C}$, para as amostras de emulsão preparadas com extrato de soja com teor de sólidos variando de 8 a 12\%, enquanto que a estabilidade da emulsão preparada com extrato de $6 \%$ de sólidos foi inferior, provavelmente em virtude do menor conteúdo de proteínas e fosfolipídios, que apresentam efeito favorável na estabilidade da emulsão. Entretanto, o extrato de soja com $12 \%$ de sólidos apresentou alta viscosidade, o que dificultou a preparação da emulsão, e desta maneira foi descartado para os ensaios com molho cremoso.

Com relação à pressão de homogeneização para as amostras de emulsão preparadas com extrato com $6 \%$ de sólidos, observou-se que uma melhor consistência da emulsão foi obtida a 2000 e 3000 psi, em relação à pressão de 1000 psi e, desta maneira, esta última condição não foi avaliada para os outros extratos de soja.

Para as amostras de emulsão preparadas com extrato com extrato de soja com $8 \%$ de sólidos, os resultados de estabilidade foram semelhantes para as pressões de homogeneização de 2000 a 4000 psi e não foram percebidas vantagens quanto à consistência desta última condição que não foi utilizada na comparação da emulsão com extrato com 10\% de sólidos.

Em geral, a $10{ }^{\circ} \mathrm{C}$, houve uma tendência de maior estabilidade para a emulsão preparada com extrato de $10 \%$ de sólidos, que foi selecionado para os ensaios posteriores. Observou-se que houve efeito da pressão de homogeneização e da proporção entre extrato de soja e óleo na estabilidade da emulsão.

A Figura 1 apresenta a análise reológica da emulsão preparada com extrato de $10 \%$ de sólidos (para o primeiro ciclo). Observou-se comportamento semelhante para as amostras nas pressões de homogeneização de 2000 e 3000 psi, na mesma relação extrato:óleo. Entretanto, aumentando-se a quantidade de óleo na emulsão, ocorreu um aumento de viscosidade.

Aplicando-se o modelo da lei de potência aos resultados, obteve-se um índice de comportamento reológico (n) menor que 1, indicando comportamento pseudoplástico. Foi observado ainda um comportamento tixotrópico do material, caracterizado por uma histerese da curva, quando se observa o segundo ciclo da análise reológica e, neste caso, optou-se pela apresentação da curva apenas para o primeiro ciclo. Comportamento semelhante foi observado para emulsões preparadas com leite de soja (MOTHE; AZEVEDO; ANTONIASSI, 2003) e para maionese (DEPREE; SAVAGE, 2001; RAO, 1992; STERN; VALENTOVA; POKORNY, 2001).

Tabela 1. Estabilidade da emulsão as temperaturas de -25 e $10^{\circ} \mathrm{C}$.

\begin{tabular}{|c|c|c|c|c|}
\hline \multirow[t]{2}{*}{$\begin{array}{c}\text { Pressão de homogeneização } \\
\text { da emulsão (psi) }\end{array}$} & \multirow[t]{2}{*}{$\begin{array}{c}\text { Teor de sólidos do extrato } \\
\text { de soja }(\% \mathrm{p} / \mathrm{v})\end{array}$} & \multirow[t]{2}{*}{$\begin{array}{c}\text { Relação extrato de } \\
\text { soja:óleo de soja (v/v) }\end{array}$} & \multicolumn{2}{|c|}{ Tempo de estabilidade da emulsão } \\
\hline & & & Horas (temperatura $-25^{\circ} \mathrm{C}$ ) & Semanas (temperatura $10^{\circ} \mathrm{C}$ ) \\
\hline 1000 & 6 & $60: 40$ & $<24$ & $<3$ \\
\hline 2000 & 6 & $60: 40$ & $<24$ & $<3$ \\
\hline 3000 & 6 & $60: 40$ & $<24$ & $<3$ \\
\hline 3000 & 6 & $40: 60$ & $<24$ & $>3$ \\
\hline 2000 & 8 & $50: 50$ & $<48$ & $>3$ \\
\hline 2000 & 8 & $60: 40$ & $<48$ & $>3$ \\
\hline 2000 & 8 & $70: 30$ & $<48$ & $<3$ \\
\hline 3000 & 8 & $50: 50$ & $<48$ & $<3$ \\
\hline 3000 & 8 & $60: 40$ & $<48$ & $<3$ \\
\hline 3000 & 8 & $70: 30$ & $<48$ & $>3$ \\
\hline 4000 & 8 & $50: 50$ & $<48$ & $>3$ \\
\hline 4000 & 8 & $60: 40$ & $<48$ & $>3$ \\
\hline 3000 & 10 & $50: 50$ & $<48$ & $<4$ \\
\hline 3000 & 10 & $60: 40$ & $<48$ & $<4$ \\
\hline 3000 & 10 & $70: 30$ & $<48$ & $>4$ \\
\hline 2000 & 10 & $70: 30$ & $>72$ & $>4$ \\
\hline 2000 & 10 & $60: 40$ & $>72$ & $>4$ \\
\hline 2000 & 10 & $50: 50$ & $<72$ & $<2$ \\
\hline 2000 & 12 & $70: 30$ & $>72$ & $<3$ \\
\hline 2000 & 12 & $60: 40$ & $>72$ & $>4$ \\
\hline 2000 & 12 & $50: 50$ & $>72$ & $<3$ \\
\hline 3000 & 12 & $50: 50$ & $<48$ & $<3$ \\
\hline 3000 & 12 & $60: 40$ & $<48$ & $<3$ \\
\hline 3000 & 12 & $70: 30$ & $<48$ & $>3$ \\
\hline
\end{tabular}


Quanto ao ajuste dos resultados (do primeiro ciclo) à lei de potência, foi observado para as amostras de emulsão, coeficiente de determinação $\left(\mathrm{R}^{2}\right)$ maior que 0,99 .

Resultados semelhantes foram obtidos para o comportamento reológico das amostras de emulsão preparadas com extrato com $8 \%$ de sólidos.

A partir dos resultados de estabilidade e de comportamento reológico, os ensaios posteriores com molho cremoso formulado com açúcar, sal e espessantes foram realizados utilizandose extrato de soja integral com $10 \%$ de sólidos e pressão de homogeneização do molho de 3000 psi.

\subsection{Estabilidade e comportamento reológico do molho cremoso}

As características das amostras de molho cremoso e os resultados de estabilidade estão relatados na Tabela 2 .

Nas amostras de molho cremoso com adição de sal, açúcar e espessantes/estabilizantes, observou-se que a estabilidade a $-25{ }^{\circ} \mathrm{C}$ foi influenciada pela relação extrato:óleo, sendo que as amostras com maior teor de óleo apresentaram menor estabilidade.

Nas amostras com adição de amido modificado e celulose microcristalina, a estabilidade foi semelhante para as três amostras de diferentes relações extrato:óleo e não promoveram melhoria da estabilidade, em relação aos demais aditivos utilizados.

Com relação às amostras de molho preparadas com o óleo de soja, quando a CMC, goma xantana e maltodextrina foram utilizadas como estabilizantes, maior estabilidade a $-25^{\circ} \mathrm{C}$ foi observada na proporção 70:30 (extrato:óleo). Como os resultados foram semelhantes para as duas marcas de goma xantana, optouse pela sequência do experimento apenas com a marca A.

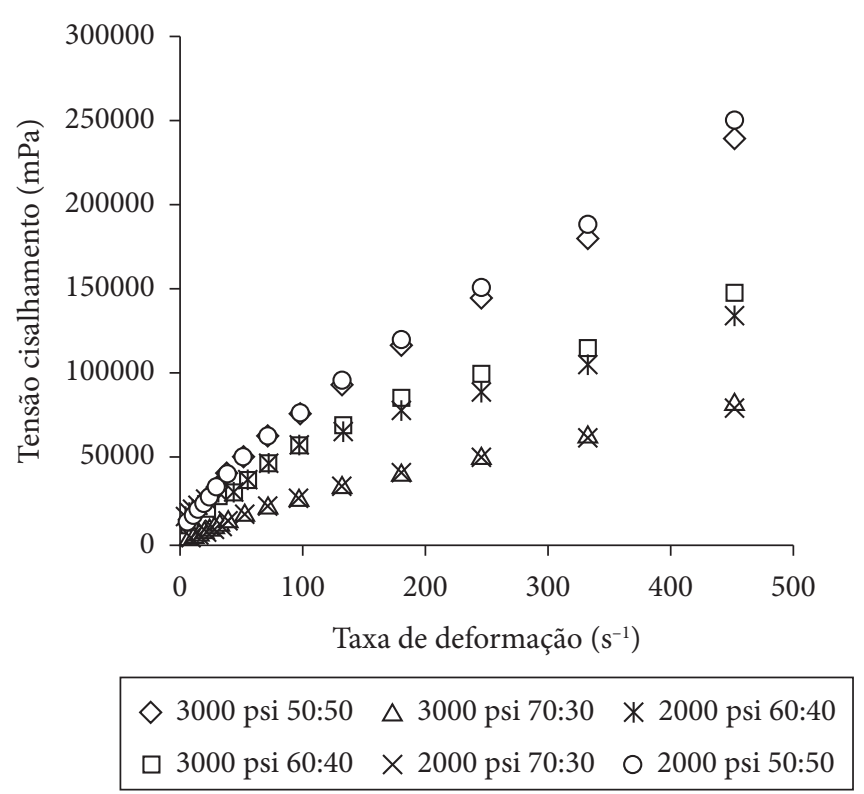

Figura 1. Comportamento reológico (primeiro ciclo) de emulsões preparadas sob pressão de homogeneização de 2000 e 3000 psi com extrato de soja (10\% de sólidos) e óleo nas relações de 50:50, 60:40 e $70: 30(\mathrm{v} / \mathrm{v})$.

Tabela 2. Estabilidade do molho cremoso elaborado com óleos de soja e girassol com vários espessantes.

\begin{tabular}{|c|c|c|c|c|}
\hline \multirow[t]{2}{*}{ Espessante } & \multirow{2}{*}{$\begin{array}{c}\text { Formulação (de extrato de soja* } \\
\text { volume/óleo de soja volume) }\end{array}$} & \multirow[t]{2}{*}{ Óleo } & \multicolumn{2}{|c|}{ Tempo de estabilidade do molho cremoso } \\
\hline & & & Horas a $-25^{\circ} \mathrm{C}$ & Semanas a $10^{\circ} \mathrm{C}$ \\
\hline Celulose microcristalina & $70: 30$ & soja & $<48$ & $>6$ \\
\hline Celulose microcristalina & $60: 40$ & soja & $<48$ & $>6$ \\
\hline Celulose microcristalina & $50: 50$ & soja & $<48$ & $>6$ \\
\hline CMC & $70: 30$ & soja & $>72$ & $>3$ \\
\hline CMC & $60: 40$ & soja & $<48$ & $>3$ \\
\hline $\mathrm{CMC}$ & $50: 50$ & soja & $<24$ & $>3$ \\
\hline Goma xantana (marca A) & $70: 30$ & soja & $<72$ & - \\
\hline Goma xantana (marca A) & $60: 40$ & soja & $<24$ & - \\
\hline Goma xantana (marca A) & $50: 50$ & soja & $<48$ & - \\
\hline Goma xantana (marca B) & $70: 30$ & soja & $>72$ & $>4$ \\
\hline Goma xantana (marca B) & $60: 40$ & soja & $<48$ & $>4$ \\
\hline Goma xantana (marca B) & $50: 50$ & soja & $<48$ & $>4$ \\
\hline Amido modificado & $70: 30$ & soja & $<24$ & $>4$ \\
\hline Amido modificado & $60: 40$ & soja & $<24$ & $>4$ \\
\hline Amido modificado & $50: 50$ & soja & $<24$ & $>4$ \\
\hline Maltodextrina & $70: 30$ & soja & $>72$ & $<5$ \\
\hline Maltodextrina & $60: 40$ & soja & $<72$ & $>5$ \\
\hline Maltodextrina & $50: 50$ & soja & $<48$ & $>5$ \\
\hline Goma xantana (marca A) & $70: 30$ & girassol & $>72$ & $>6$ \\
\hline $\mathrm{CMC}$ & $70: 30$ & girassol & $>72$ & $>6$ \\
\hline Maltodextrina & $70: 30$ & girassol & $>72$ & $>5$ \\
\hline
\end{tabular}

*Extrato de soja com $10 \%$ de sólidos e pressão de homogeneização de emulsão de 3000 psi (-) não determinado CMC - carboximetilcelulose. 
Para as amostras de molho utilizando-se o óleo de girassol, os resultados foram semelhantes para as três proporções de extrato:óleo testadas.

De acordo com Depree e Savage (2001), nas emulsões do tipo óleo em água como a maionese, a estabilidade depende do tamanho e da quantidade de gotículas de óleo.

A estabilidade a $10{ }^{\circ} \mathrm{C}$ foi variável, mas com menor estabilidade para as amostras de CMC.

Para análise reológica e sensorial das amostras de molho cremoso, optou-se pela comparação entre as amostras preparadas na relação extrato:óleos de soja e girassol de 70:30 que apresentaram maior redução calórica em relação à maionese tradicional.

A Figura 2 apresenta a análise reológica do molho cremoso preparado com extrato de $10 \%$ de sólidos (para o primeiro ciclo)

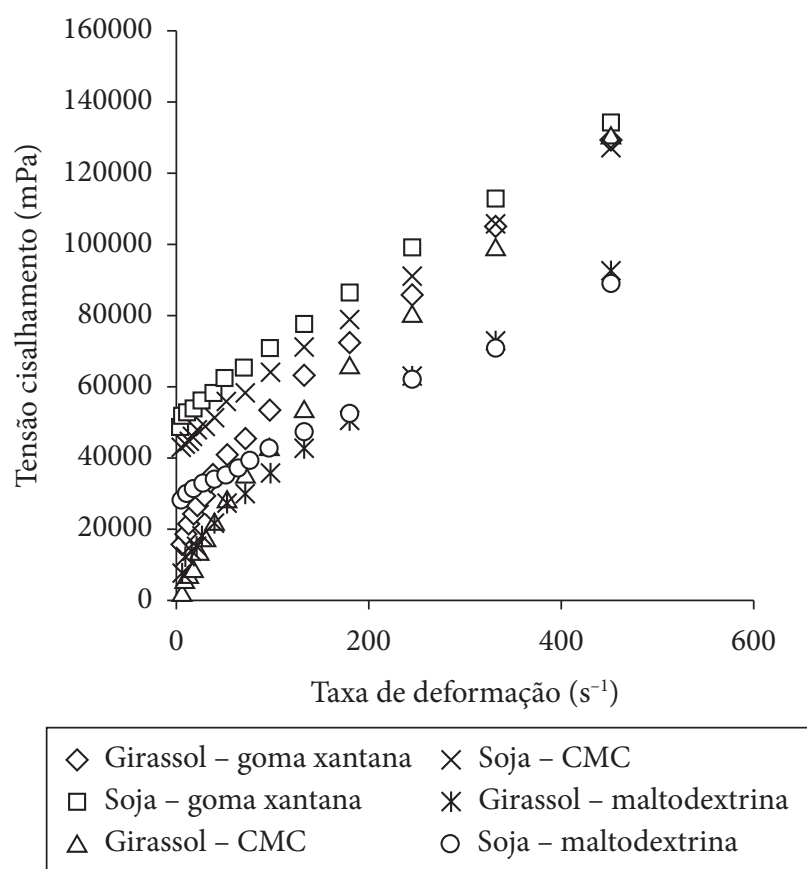

Figura 2. Comportamento reológico (primeiro ciclo) do molho cremoso preparado sob pressão de homogeneização de 3000 psi na relação 70:30 de extrato de soja ( $10 \%$ de sólidos):óleos de soja ou girassol e diversos estabilizantes (carboximetilcelulose - CMC, goma xantana e maltodextrina). e pressão de homogeneização de 3000 psi, na mesma relação extrato:óleo de 70:30 e óleos de soja e girassol.

Foi observado comportamento reológico semelhante entre as amostras obtidas com os óleos de soja e girassol. A viscosidade foi superior para as amostras com goma xantana e CMC, tendo sido observada menor viscosidade para as amostras contendo maltodextrina. Nas emulsões do tipo óleo em água, a viscosidade depende do tamanho da gotícula de óleo e da presença de espessantes na fase contínua (DEPREE; SAVAGE, 2001; STERN; VALENTOVA; POKORNY, 2001).

Quanto ao ajuste dos resultados (do primeiro ciclo) à lei de potência, foi observado para as amostras de molho cremoso, coeficiente de determinação $\left(R^{2}\right)$ entre 0,9 a 0,99 .

\subsection{Avaliação sensorial do molho cremoso}

As médias e erros padrão em relação à preferência quanto ao sabor e quanto à consistência das amostras, assim como o resultado para a intenção de compra dos produtos preparados com óleo de soja e óleo de girassol, são apresentados na Tabela 3.

Os resultados obtidos revelaram que não houve diferença significativa $(\mathrm{p}<0,05)$ para a preferência quanto ao sabor, consistência e intenção de compra entre os molhos com óleo de soja processados com goma xantana, CMC e maltodextrina como espessantes. A média em relação ao sabor variou de 6,7 a 6,9, ficando entre "gostei moderadamente" e "gostei ligeiramente" na escala utilizada. A média alcançada para a intenção de compra dos consumidores foi 4,7 ficando ligeiramente acima da região de indefinição na escala de sete pontos utilizada ("provavelmente compraria").

As médias alcançadas pelos molhos processados com óleo de girassol foram bastante semelhantes àquelas dos produtos processados com óleo de soja, revelando que o óleo empregado não afetou a avaliação feita pelos consumidores para os atributos estudados. A média para a consistência foi ligeiramente superior para goma xantana, embora não tenha havido diferença estatística entre as amostras.

Stern, Valentova e Pokorny (2001) relataram também que não houve correlação entre viscosidade aparente de maionese e avaliação sensorial de sabor e textura, conforme foi observado no presente estudo, na avaliação de preferência quanto ao sabor e consistência do molho cremoso.

Tabela 3. Média e erro padrão* da preferência quanto ao sabor, consistência e intenção de compra das amostras de molho cremoso com óleos de soja e girassol, usando diferentes espessantes.

\begin{tabular}{|c|c|c|c|c|c|c|}
\hline \multirow[t]{2}{*}{ Estabilizante/espessante } & \multicolumn{3}{|c|}{ Óleo de soja } & \multicolumn{3}{|c|}{ Óleo de girassol } \\
\hline & $\begin{array}{c}\text { Preferência } \\
\text { sabor }^{1}\end{array}$ & $\begin{array}{c}\text { Preferência } \\
\text { consistência }^{2}\end{array}$ & $\begin{array}{c}\text { Intenção de } \\
\text { compra }^{3}\end{array}$ & $\begin{array}{c}\text { Preferência } \\
\text { sabor }^{1}\end{array}$ & $\begin{array}{c}\text { Preferência } \\
\text { consistência }\end{array}$ & $\begin{array}{c}\text { Intenção de } \\
\text { compra }^{3}\end{array}$ \\
\hline Goma xantana & $6,9(0,16)$ & $7,1(0,17)$ & $4,7(0,21)$ & $6,9(0,16)$ & $7,6(0,17)$ & $4,9(0,19)$ \\
\hline $\mathrm{CMC}$ & $6,8(0,18)$ & $7,0(0,17)$ & $4,6(0,20)$ & $6,8(0,18)$ & $7,3(0,17)$ & $4,8(0,20)$ \\
\hline Malto dextrina & $6,7(0,16)$ & $7,1(0,18)$ & $4,5(0,21)$ & $6,9(0,15)$ & $7,2(0,18)$ & $4,9(0,20)$ \\
\hline
\end{tabular}

${ }^{1,2}$ Escala estruturada de 9 pontos (gostei extremamente a desgostei extremamente); ${ }^{3}$ Escala estruturada de 7 pontos (definitivamente compraria a definitivamente não compraria); ${ }^{\star}$ Valor de erro padrão entre parênteses; e CMC - carboximetilcelulose. 
Não houve correlação entre a viscosidade das amostras analisadas, conforme observado na análise reológica e a aceitação do consumidor, pois menor viscosidade foi observada para as amostras preparadas com CMC (Figura 2).

Considerando os comentários feitos pelos participantes em relação às características favoráveis nos molhos com óleo de soja, os seguintes aspectos foram mencionados: bastante leve, consistência agradável, sabor, cremosidade. Dentre as características apontadas como "desgostadas" nos produtos apareceram: pouco tempero, pouco sal, muito ácida, cor, sabor.

Os comentários dos consumidores quanto ao molho processado com óleo de girassol foram semelhantes. O resultado considerado mais importante para o produto foi a ausência de comentários de rejeição devido à presença de extrato de soja. Em geral, para os produtos processados com soja, ocorre percepção da adição de derivados de soja, ocorrendo inclusive rejeição. Por outro lado, declarações de rótulo com apelos nutricionais influenciam a preferência pelos consumidores (WANSINK et al., 2000).

Em relação aos três espessantes testados, foi observado o mesmo nível de aceitabilidade quanto ao sabor e consistência. Assim, para este tipo de produto, a escolha entre os espessantes e o óleo pode ser baseada no menor custo.

\subsection{Análise nutricional do extrato e do óleo}

Os resultados da composição do extrato de soja integral homogeneizado com $10 \%$ de sólidos estão apresentados na Tabela 4. Os resultados encontrados estão próximos aos relatados por Paula (1991) e por Felberg et al. (2004) que analisaram respectivamente, amostras de extrato de soja hidrossolúvel com 10,60\% de sólidos e extrato de soja integral com 7\% de sólidos. De acordo com Lakshmanan, Lamballerie e Jung (2006), a composição da bebida de soja depende da relação de soja:água na etapa de trituração.

Considerando-se a contribuição de lipídios, proteína e carboidratos provenientes do extrato integral homogeneizado (Tabela 4) e a quantidade de óleo adicionada, as amostras de molho cremoso 70:30, 60:40 e 50:50 apresentaram uma redução calórica, em relação à maionese tradicional (com 70\% de óleo), respectivamente de, 60 , 48 e $36 \%$. O molho cremoso 70:30 apresentou uma redução em calorias comparável a alguns produtos comerciais brasileiros com teor reduzido de óleo, mas apresenta como vantagem um maior teor proteico e é livre de colesterol. Muitos destes produtos utilizam ovos em sua formulação.

Tabela 4. Composição centesimal de extrato de soja integral homogeneizado.

\begin{tabular}{cc}
\hline Determinação & g.100 g-1 \\
\hline Umidade & 90,26 \\
Proteínas & 3,98 \\
Lipídeos & 2,60 \\
Fibra bruta & 0,41 \\
Cinzas & 0,39 \\
Carboidratos & 2,36 \\
\hline
\end{tabular}

${ }^{\star}$ Calculado por diferença $=(100-$ umidade - proteína - lipídios - cinzas - fibra $)$.
Os resultados da composição e características dos óleos utilizados estão apresentados na Tabelas 5 e 6.

Os resultados obtidos para índices de peróxido e acidez para os óleos de soja e girassol foram baixos, característicos de óleos refinados e atendem à legislação brasileira (BRASIL, 2005).

Os resultados para os índices de estabilidade oxidativa (Rancimat) foram respectivamente de 15,33 e 4,12 horas, para os óleos de soja e girassol (Tabela 5).

A composição em ácidos graxos dos óleos de soja e girassol (Tabela 6) atende aos parâmetros de identidade do Codex Alimentarius (2001). O teor de ácidos graxos saturados foi menor para o óleo de girassol. Os resultados de oleico e linoleico são semelhantes para as duas amostras, mas o teor de linolênico é superior para o óleo de soja enquanto que foi detectado até o nível de $0,29 \%$ no óleo de girassol. Apesar do maior teor de linolênico no óleo de soja, sua estabilidade foi superior ao óleo de girassol. A presença de ácidos graxos com duplas ligações trans presentes no óleo de soja decorre de isomerização na etapa de desodorização do óleo. A estabilidade oxidativa é um parâmetro global da resistência à oxidação, que depende da composição em ácidos graxos, do teor de antioxidantes naturais, da qualidade da matéria-prima, do processo de refino, entre outros fatores (ANTONIASSI, 2001).

O óleo de girassol apresentou uma menor estabilidade oxidativa em relação ao óleo de soja, fator que poderá afetar a

Tabela 5. Características dos óleos de soja e girassol.

\begin{tabular}{lcc}
\hline & Óleo de soja & Óleo de girassol \\
\hline $\begin{array}{l}\text { Índice de peróxido (meq.kg }{ }^{-1} \text { ) } \\
\begin{array}{l}\text { Teor de ácidos graxos livres (\%) } \\
\text { expresso como ácido oleico }\end{array}\end{array}$ & 0,48 & 0,55 \\
$\begin{array}{l}\text { Índice de estabilidade oxidativa } \\
\text { em horas (Rancimat a } 98^{\circ} \mathrm{Ce} \\
\text { fluxo de ar de } 8,33 \mathrm{~L} / \text { hora) }\end{array}$ & 15,33 & 0,06 \\
\hline
\end{tabular}

Tabela 6. Composição em ácidos graxos (\%) dos óleos de soja e de girassol.

\begin{tabular}{lcc}
\hline \multicolumn{1}{c}{ Ácidos graxos } & Óleo de soja & Óleo de girassol \\
\hline C14:0 & nd & 0,03 \\
C16:0 & 9,47 & 4,29 \\
C16:1 & nd & 0,05 \\
C18:0 & 3,58 & 4,32 \\
C18:1 & 25,04 & 29,30 \\
C18:2 t & 0,66 & 0,56 \\
C18:2 & 53,69 & 59,01 \\
C20:0 & 0,52 & 0,46 \\
C18:3 t & 1,00 & nd \\
C18:3 & 4,96 & 0,29 \\
C20:1 & nd & 0,26 \\
C22:0 & 0,76 & 1,05 \\
C24:0 & 0,32 & 0,33 \\
Não identificado & - & 0,06 \\
\hline
\end{tabular}

nd = não detectado; e t $=$ isômero com duplas ligações trans. 
vida de prateleira do produto. Depree e Savage (2001) relataram que o tipo de óleo influencia a estabilidade oxidativa das amostras de maionese. Como os resultados estão restritos a estas amostras de óleo utilizadas no experimento, a vida de prateleira do produto dependerá de estudos posteriores.

\section{Conclusões}

Os extratos de soja integral homogeneizados com 8 e 10\% de sólidos promoveram maior estabilidade da emulsão.

O aumento da pressão de homogeneização e da quantidade de óleo promoveu aumento de viscosidade da emulsão.

Os espessantes mais adequados para aumento de estabilidade foram a maltodextrina, CMC e goma xantana e maior viscosidade aparente foi obtida com os dois últimos espessantes.

Não houve diferença na preferência quanto a sabor, consistência e intenção de compra para o molho cremoso preparado com óleos de girassol e soja e os estabilizantes maltodextrina, CMC, e goma xantana.

Os resultados obtidos pela análise sensorial permitem concluir que o produto alcançou satisfatório desempenho entre os participantes do teste, constituindo uma alternativa para o consumidor que deseja ingerir alimentos mais saudáveis.

As condições selecionadas para elaboração de molho cremoso com boas características de estabilidade, de consistência e sensoriais seriam com extrato de soja integral com $10 \%$ de sólidos, relação extrato:óleo de 70:30, utilizando-se com espessantes, a maltodextrina, CMC ou goma xantana.

\section{Agradecimentos}

Os autores agradecem a bolsa de apoio técnico da FAPERJ (Fundação de Amparo à Pesquisa do Estado do Rio de Janeiro) para o primeiro autor.

\section{Referências bibliográficas}

AKOH, C. C. Fat replacers: present and future. In: LATIN AMERICAN CONGRESS AND EXHIBIT ON FATS AND OILS PROCESSING, 6., 1995, Campinas. Proceedings... Campinas: UNICAMP, 1995. p. 83-94.

ANTONIASSI, R. Métodos de avaliação da estabilidade oxidativa de óleos e gorduras. Boletim do CEPPA, Curitiba, v. 19, n. 2, p. 353, 2001.

ASSOCIATION OF OFFICIAL ANALYTICAL CHEMISTS - AOAC. Official methods of analysis of association of Official Analytical Chemists International. $18^{\text {th }}$ ed. Arlington: AOAC International, 2005.

AMERICAN OIL CHEMISTS' SOCIETY - AOCS. Official methods and recommended practices of the American Oil Chemists' Society. Champaign: AOCS, 2004.
BRASIL. Resolução RDC ANVISA/MS nº. 270, de 22 de setembro de 2005. Regulamento técnico para óleos vegetais, gorduras vegetais e creme vegetal. Diário Oficial da União, Brasília, DF, 23 set. 2005. Seção 1.

CODEX ALIMENTARIUS. Fats, Oils and related products. $2^{\text {nd }}$ ed. Roma, 2001. v. 8.

DEPREE, J. A.; SAVAGE, G. P. Physical and flavour stability of mayonnaise. Trends in Food Science \& Technology, v. 12, n. 5/6, p. 157-163, 2001.

FELBERG, I. et. al. Bebida mista de extrato de soja integral e castanha-do-brasil: caracterização físico-química, nutricional e aceitabilidade do consumidor. Alimentos \& Nutrição, v. 15, n. 2, p. 163-174, 2004.

GIESE, J. Fats, Oils and fat replacers. Food Technology, n. 4, p. 78-84, 1996.

GROSSKLAUS, R. Fat replacers - requirements from a nutritional physiological point of view. Fett/Lipid, v. 98, n. 4, p. 136-141, 1996.

HARTMAN, L; LAGO, R. C. A. A rapid preparation of fatty acid methyl esthers from lipids. Laboratory Practice, v. 22, n. 8 , p. 475-476, 1973.

LAKSHMANAN, R.; LAMBALLERIE, M.; JUNG, S. Effect of soybean-to-water ratio and $\mathrm{pH}$ on pressurized soymilk properties. Journal of Food Science, v. 71, n. 9, p. E384-E391, 2006.

MOTHE, C. G.; AZEVEDO, A. D.; ANTONIASSI, R. Rheological characterization of emulsions from soymilk. In: INTERNATIONAL SYMPOSIUM ON FOOD RHEOLOGY AND STRUCTURE, 3., 2003 , Zurich. Proceedings... Zurich: Swiss Federal Institute of Techonology, 2003. p. 531-532

PATEL, A. A.; GUPTA, S. K. Studies on a soy-based low-fat spread. Journal of Food Science, v. 53, n. 2, p. 455-459, 1988.

PAULA, C. D. Estudo de processo para elaboração de maionese de soja e sua utilização como ingrediente de patê. 1991. $122 \mathrm{f}$. Dissertação (Mestrado em Ciências dos Alimentos) - Escola Superior de Agricultura de Lavras, Lavras, 1991.

RAO, M. A. Viscoelastic properties of mayonnaises and salad dressings. In: RAO, M. A.; STEFFE, J. F. (Eds.). Viscoelastic properties of foods. New York: Elsevier Applied Science, 1992. p. 355-370.

SLOAN, A. E. Top 10 global food trends. Food Technology, v. 59, n. 4, p. 20-32, 2005.

STERN, P.; VALENTOVA, H.; POKORNY, J. Rheological properties and sensory texture of mayonnaise. European Journal of Lipid Science and Technology, v. 103, n. 1, p. 23-28, 2001.

STEWART-KNOX, B.; MITCHELL, P. What separates winners from the losers in new product development? Trends in Food Science \& Technology, v. 14, p. 58-64, 2003.

WANG, S. H.; PAULA, C. D.; MORAES, M. A. C. Elaboracion de mayonesa de soya y su utilizacion como ingrediente de pate. Alimentaria, n. 12, p. 67-71, 1991.

WANSINK, B. et. al. How soy labeling influences preference and taste. International Food and Agribusiness Management Review, v. 3, p. 85-94, 2000. 